\title{
Correlated GNSS and temperature measurements at 10-minute intervals on the Severn Suspension Bridge
}

\author{
G. W. Roberts ${ }^{1}$ (D) C. J. Brown ${ }^{2}$ - X. Tang ${ }^{3}$
}

Received: 9 August 2016 / Accepted: 5 April 2017

(C) The Author(s) 2017. This article is an open access publication

\begin{abstract}
Global Navigation Satellite System (GNSS) data were gathered on the 998-m-long Severn Suspension Bridge main span. The antennas were located on the tops of the four support towers, as well as five locations on the suspension cables; data were gathered at rates of 10 and $20 \mathrm{~Hz}$. In addition, air and steel temperatures were gathered every $10 \mathrm{~min}$. The GNSS data were processed in an On The Fly manner relative to a reference receiver located on a fixed position adjacent to the Bridge, and the resulting dataset was compared to the air and steel temperature data measurements, and correlations reported. Moving average filters that eliminate shortterm movements due to wind loading and traffic loading were applied to the GNSS data, resulting in the longer-term deflections due to temperature changes every $10 \mathrm{~min}$. The temperature over the 3 days varied by up to $10^{\circ} \mathrm{C}$, and movements of the order of decimetres were seen. Clear numerical correlations between the changes in temperature and the changes in height are presented when analysed at these 10-min intervals, suggesting that temperature compensation in structural health monitoring systems could be readily applied, resulting in a sustainable structure.
\end{abstract}

Keywords GNSS · Bridge deflections · Deformation monitoring

\section{G. W. Roberts}

Gethin.roberts@nottingham.ac.uk

1 University of Nottingham, Nottingham, UK

2 Brunel University London, Uxbridge, London, UK

3 The University of Nottingham Ningbo, 199 Taikang East Road, Ningbo 315100, China

\section{Introduction}

Structural health monitoring (SHM) of structures, and in particular long-span bridges, is becoming an important topic. Since the dramatic failure of the Tacoma Narrows Bridge on the 7th November 1940 (Matsumoto et al. 2003), a succession of bridges have failed, some of which have also collapsed or failed beyond repair. Many bridges still rely on periodic visual inspections as the main method of finding faults. In December 2015, fractures were identified in the truss and links on the Forth Road Bridge in Scotland. This led to 12 weeks of disruption to traffic flow, which included the unprecedented closure of the Bridge to all traffic and pedestrians for a period of 4 weeks. This was classed as an event of national significance by the Scottish Parliament, as over 100,000 people use the Bridge every day (Shackman and Climie 2016). Suspension and cable-stayed bridges are becoming longer with improved understanding and engineering capabilities. The world's longest suspension bridge, the Akashi Kaikyo Bridge in Japan, currently lies with a main span length of 1991 m (Kitagawa 2004). The cost of constructing such structures is very large. For example, the estimated cost of building the second Severn road crossing, called the Queensferry Bridge, is $£ 1.3$ billion (Shackman and Climie 2016). The development of SHM schemes, using automated data gathering and analysis, could play an important part in possibly detecting faults early and reducing the chances of catastrophic failures. This could also result in economic benefits in being able to prolong the life of such a structure, hence making the structure more sustainable. The Queensferry Bridge is currently under construction, mainly due to the uncertainty of the health of the first. Due to the extensive construction cost and time to build such a structure, decisions to plan and build have to be made well in advance. The Queensferry Bridge will have taken 10 years in total to conduct feasibility studies, plan and build the Bridge (Shackman and Climie 2016). It 
could be argued that an extensive SHM could improve such a situation, by extending the life and improving confidence in the knowledge of existing bridges.

Various sensors and technologies have been used and developed in order to gain more knowledge about specific bridges. These range from simple anemometer-based systems that allow traffic flow and types to be restricted under predetermined wind loading, to extensive multi-sensor systems. Most existing approaches rely on simple and complex models of such structures, such as finite element models (FEM), which can be used to calculate the effect on the structure during various loading scenarios due to traffic, wind, temperature, etc. These models are based on theoretical values of how small elements of the structure behave, and all these small elements are brought together in the model to calculate how the structure as a whole behaves. Real data is sometimes used to evaluate such models, but seemingly not very often.

Various sensors could be used to monitor such structures, including traditional surveying equipment such as levels and total stations. However, such surveying relies on the structure being relatively still. Motorised total stations have been used to measure the deflections of such structures. However, due to the relatively low speed of data gathering, and the imprecision of the time of data gathering, this technique is not very effective. The use of photogrammetry, and in particular video, has been used on the Humber Bridge (Stephen et al. 1993) as well as other smaller structures (Ferrer et al. 2016). Such an approach was used to measure the vertical movements of the structure, by measuring the pixel by pixel movement of a large target located on the bridge. Again, this technique has limitations in terms of the ability to easily measure $3 \mathrm{D}$ coordinates and the distance limitations between the camera, on the land, and the targets on the bridge. Other sensors embedded into the structure have been investigated, such as tilt sensors and accelerometers, and more recently Global Positioning System (GPS) and Global Navigation Satellite System (GNSS). The integration of such sensors, in particular, can offer an improved solution, being able to eliminate the drift in the accelerometer though the GNSS data, as well as reducing the noise in the GNSS data through using the accelerometer data to filter the GNSS data. Also, the data can be densified to $1000 \mathrm{~s}$ of Hertz, if required, using the accelerometer data.

The use of laser scanners could be used to measure and create 3D models of such structures, but this is only if the structure is relatively still. Due to the survey time required when using laser scanners, typically up to a few minutes per scan, the structure is most likely to move and deflect in this time, and the resulting scans will include such noise. Laser scanners are, therefore, thought not to be suitable for deflection monitoring of structures over time.

A relatively new piece of equipment, using radar technologies, is currently being investigated for deformation monitoring and deflection monitoring of structures (Atzeni et al.
2010; Negulescu et al. 2013; Luzi et al. 2014), and small span bridges in particular (Ferrer et al. 2016; Gentile and Cabboi 2015). Such techniques use microwave interferometry-based systems. These ground-based systems are mobile, and allow data to be gathered at a rate of $200 \mathrm{~Hz}$ with possible precisions of $0.1 \mathrm{~mm}$ (Ferrer et al. 2016). Such technology looks promising in being able to be used as part of a SHM in order to measure natural frequencies as well as deflections very precisely. However, typically deflections in one direction are measured, and obtaining 3D deflections is complicated. The distance from the sensor location, typically on the land adjacent to the bridge, to the targets located on the bridge is also limited.

GNSS has been used to monitor the deflections of longspan bridges for over 20 years. The authors have conducted various field tests and analyses on a number of bridges, including the Humber Bridge in the UK (Ashkenazi et al. 1996), the Forth Road Bridge in the UK (Roberts et al. 2012), The London Millennium Bridge (Roberts et al. 2006), the Avonmouth motorway viaduct (Ogundipe et al. 2014), the Wilford Suspension Bridge in Nottingham, UK (Meo et al. 2004), and the Severn Suspension Bridge, UK (Roberts et al. 2014).

Suspension bridges are prone to movements, by design. These movements can be split into a variety of components. These include the following:

- The movements due to the natural frequencies of the bridge, which can be as low as $0.05 \mathrm{~Hz}$ or so and induced typically by the loading due to traffic or wind

- The deflections of the bridges due to loading from traffic and wind, which is of the order of up to decimetres, but over a time period of a few seconds

- The deformation of the support towers, and hence the bridge, due to long-term movements such as settlement and earthquakes

- The long-term movements of the bridge due to ambient temperature changes

This paper focusses on the comparison, and potential use, of GNSS-derived deflections with changes in air and steel temperatures. The scope of the work illustrates the possibility of using such data as part of a SHM scheme in order to detect any long-term lack of correlation which could imply that the bridge is damaged or deteriorating. This paper is a first step in such work, and it is anticipated that such data could be used to better understand such a structure. The paper also illustrates that the GNSS data is very powerful, in that by using simple filters it is possible to extract the various movements listed above and hence better understand the movements through using one type of sensor.

Previous works on the Humber Bridge and the Avonmouth M5 motorway crossing have shown results that have this type 
of temperature-induced long-term movement evident. Figure 1 illustrates results from the Humber Bridge illustrating the vertical movements at a single location during three successive days, using $12 \mathrm{~h}$ of data from each day. The 3-day results are overlapped with each other in the figure. The data from the 1st March starts at a slightly later time, due to the setup time at the start of the survey. The deflections at this location are evident in the figure, showing the Bridge moving down at the order of up to $30 \mathrm{~cm}$ due to the traffic loading. However, it can also be seen that all 3-day results gradually drop down over $12 \mathrm{~h}$. This is due to the increase in temperature and the corresponding expansion of the steelwork on the Bridge. There is no temperature data available for the $1 \mathrm{st}$ March. However, on the 2nd March, the air temperature at 09:15 was $4{ }^{\circ} \mathrm{C}$, and changed down to $1.8^{\circ} \mathrm{C}$ at $09: 40$ and finally up to $8^{\circ} \mathrm{C}$ by 15:00 (Cosser 2005). On the 4 th March, the temperature started at $14.5^{\circ} \mathrm{C}$ at $09: 00$, changed down to a minimum of $9{ }^{\circ} \mathrm{C}$ by $10: 05$ and then up to $15^{\circ} \mathrm{C}$ by $12: 00$, then again dropping to $1{ }^{\circ} \mathrm{C}$ at $14: 10$, rising again to $13^{\circ} \mathrm{C}$ at 14:50, then gradually dropping from $15: 15$ to $10^{\circ} \mathrm{C}$ at $16: 30$. It can also be seen that the height of this location on the 4th March started off at a lower location. This is because the temperature at this time was higher. The corresponding overall changes in height during these surveys are $0.166,0.188$ and $0.124 \mathrm{~m}$ during the $1 \mathrm{st}, 2 \mathrm{nd}$ and 4 th March respectively. These results illustrate that a bridge, such as the Humber Bridge, with a main span length of $1410 \mathrm{~m}$ experiences deflections of the order of decimetres when the air temperature changes by a few degrees.

Figure 2 illustrates the lateral, longitudinal and vertical deflections at a location on the M5 Avonmouth viaduct (Ogundipe et al. 2014; Roberts et al. 2014). Here, again, it can be seen that over an approximately 6-h period, the bridge moves in a mainly vertical and longitudinal direction. Again, this is thought to be due to the heating effect and expansion of the bridge.

Temperature changes, and the resulting thermal loads on bridges, are important characteristics for the serviceability limit state design of bridges. Such information is required for the design, and the ability to monitor the changes in temperature and the corresponding movements can help to create a structural health monitoring (SHM) system, in addition to helping improve future designs and understanding of such structures. Both seasonal and diurnal temperature changes result in such deflections.

Research has been carried out on the Humber Bridge (Xia et al. 2016), identifying that temperature changes are important for the understanding of the state of a bridge. A 2D FEM was established in order to model the changes in a typical section. The thermal behaviour of this section was analysed, and it was concluded that such analysis is difficult due to the complexity of such a structure.

The effect of solar radiation (Westgate et al. 2014) was analysed on the Tamar Bridge, UK. The Tamar Suspension Bridge has a main span length of $335 \mathrm{~m}$. The bridge deck and suspension cables were analysed for the effect of solar radiation. The paper concluded that the peak temperature of the structure and the cables occur at different times, due to the different material properties, as well as the surfaces' ability to absorb and lose heat. An FEM was developed, and real survey data used to compare. The survey data consisted of using a single total station to sequentially measure angles and distances to 15 targets located upon the bridge. The cycle took $10 \mathrm{~min}$, and repeated every $30 \mathrm{~min}$. During the field tests, cloud cover was reported. Ten days of displacement data were gathered, and daily results produced. These were compared to
Fig. 1 Three consecutive days of data from the same location on the Humber Bridge, illustrating the effect of temperature on the overall level of the Bridge deck (Roberts et al. 2005)

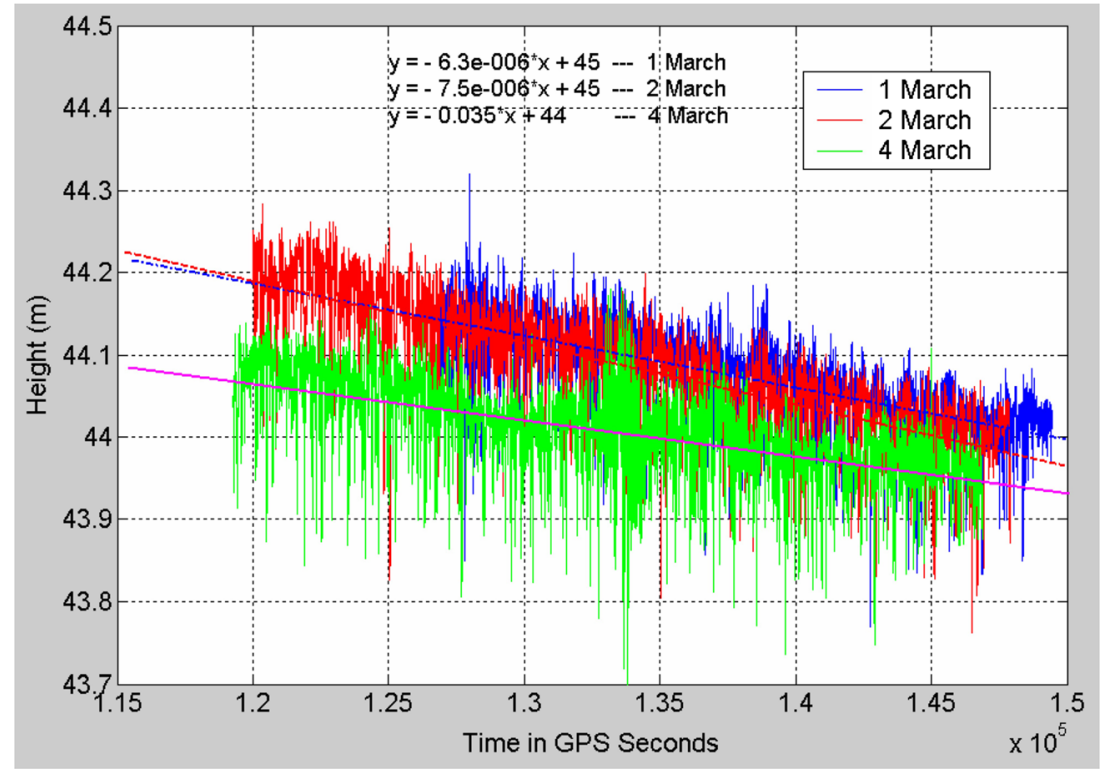




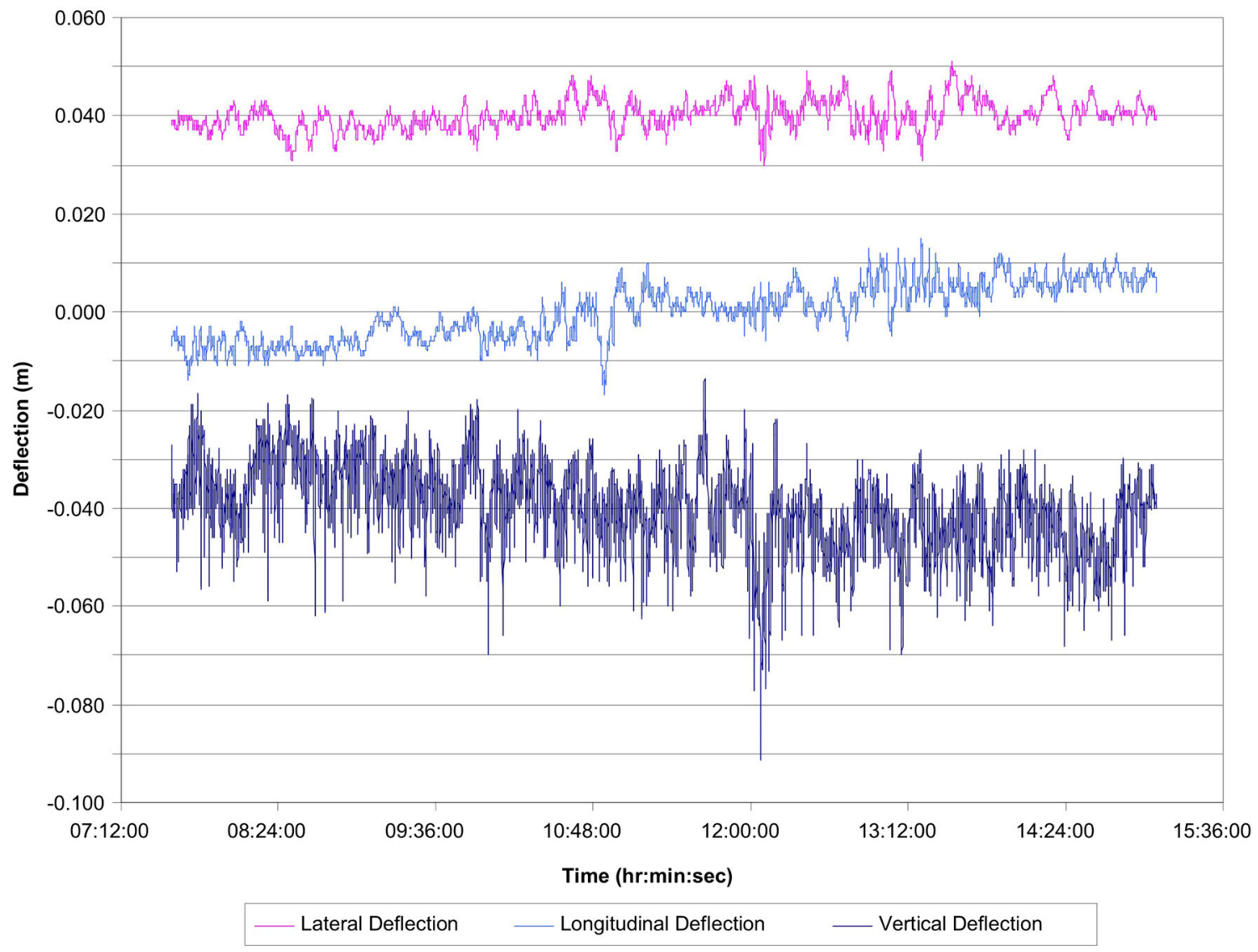

Fig. 2 Lateral, longitudinal and vertical movements of location M on the 30 November 2007, the Avonmouth viaduct (Roberts et al. 2014)

the FEM. The results included those for the cables, deck and truss. Results illustrated that the vertical movements on the bridge at the midspan were affected more by the thermal response of the suspension cable rather than the deck's response or the truss' response.

Further work was conducted on the Tamar Bridge (De Battista et al. 2015). A model of the temperature and extension relationship was developed, conclusions included that such bridges are very complex, and it is not possible to calculate the effect on every single section. However, a global model could work better.

Work has also been conducted on the Tsing Ma Bridge in Hong Kong (Xu et al. 2010). The main span's length is $1377 \mathrm{~m}$. This bridge, similarly to many large-span bridges in Asia, is fully equipped with monitoring sensors, such as GPS, thermometers, displacement transducers, anemometers and level sensing stations, all focussed on providing information towards a SHM system. Again, this research developed a daily average temperature-displacement response analysis. The cable at midspan expanded by $2.94 \mathrm{~mm} /{ }^{\circ} \mathrm{C}$ and the deck at midspan by $15.50 \mathrm{~mm} /{ }^{\circ} \mathrm{C}$.

Further work has been carried out on the Severn Suspension Bridge in the UK, and this is the topic of this paper.

\section{The Severn Bridge Survey, 2010}

The Severn Suspension Bridge is a motorway bridge that connects South Wales to just north of Bristol, in the UK. The structure took 3.5 years to construct at a cost of $£ 8$ million. The Bridge was opened on the 8th September 1966. The Bridge is $1600 \mathrm{~m}$ long, with a 988-m-long central span between two 136-m-tall towers. The suspension cables are $495 \mathrm{~mm}$ in diameter, spun from 29,000 km of $4.98 \mathrm{~mm}$ diameter cables (Fisher and Lambert 2013).

An extensive survey was carried out on the Severn Suspension Bridge in the UK in March 2010. This consisted of placing nine GNSS antennas on the Bridge itself, on the tops of the four towers as well as key locations on the suspension cables. GNSS has the advantage over a total station approach in that a number of locations can be surveyed simultaneously, with synchronised data, at rates of up to 10,20 and even $100 \mathrm{~Hz}$. The total station approach also has the disadvantage of limited range from the stable land to the survey station upon the bridge. Such GNSS measurements result in data that includes all the characteristic movements of the bridge. Figure 3 illustrates the locations of the GNSS antennas on the Severn Bridge. Thirty-metre-long antenna cables were used to connect the GNSS antennas to the receivers. This 
Fig. 3 The locations of the nine GNSS antennas on the Severn Bridge

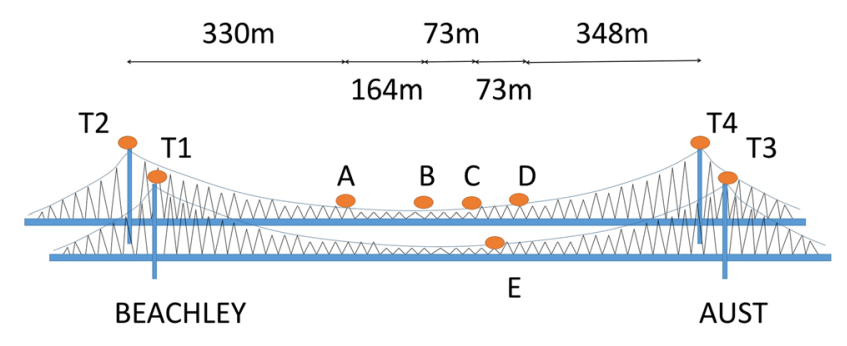

Toll Booths' Building with reference GNSS receiver located on top allowed the surveyors to be located in safe locations whilst operating the receivers. The four receivers attached to the antennas on the tops of the towers were Leica SR530 dualfrequency GPS receivers, and the receivers attached to the suspension cables were Leica 1200 dual-frequency GPS/ GLONASS receivers. The antennas used were Leica AT504 choke ring antennas on the tops of the towers, and Leica AT503 lightweight choke ring antennas on the suspension cables. Two GNSS reference stations were set up, both using Leica 1200 GNSS receivers and AT504 antennas (Roberts et al. 2014).

Data were gathered at a rate of $10 \mathrm{~Hz}$ at the SR530 receivers, and $20 \mathrm{~Hz}$ at the 1200 receivers. Details about the survey are explained further in Roberts et al. (2014). The data at locations A and B during the whole survey are used in this paper to detail the relationship between the movements at these locations and the changes in temperature. Temperature information is available at 10-min intervals, for both the air and the steel. The steel temperature was recorded at the Aust abutment. The temperature data are part of the in-service data gathered at the bridge, including wind speed and direction at various locations. The temperature data at this rate is thought to be acceptable, as it is not imagined that the temperature would fluctuate by a large amount over a 10 -min period.

\section{Data analysis}

The GPS data were processed using RTKLIB version 2.4.2 using a combined forward and backward solution (Takasu and Yasuda 2009), and converted into the coordinate system of the Bridge (Eqs. 1 and 2). Equations 1 and 2 represent the transformation of the movements in the easting (E) and northing $(\mathrm{N})$ coordinates, along with the bearing of the bridge $(\alpha)$ into
Fig. 4 Lateral, longitudinal and vertical GNSS movements at location A over a 1-h period on the 11th March 2010

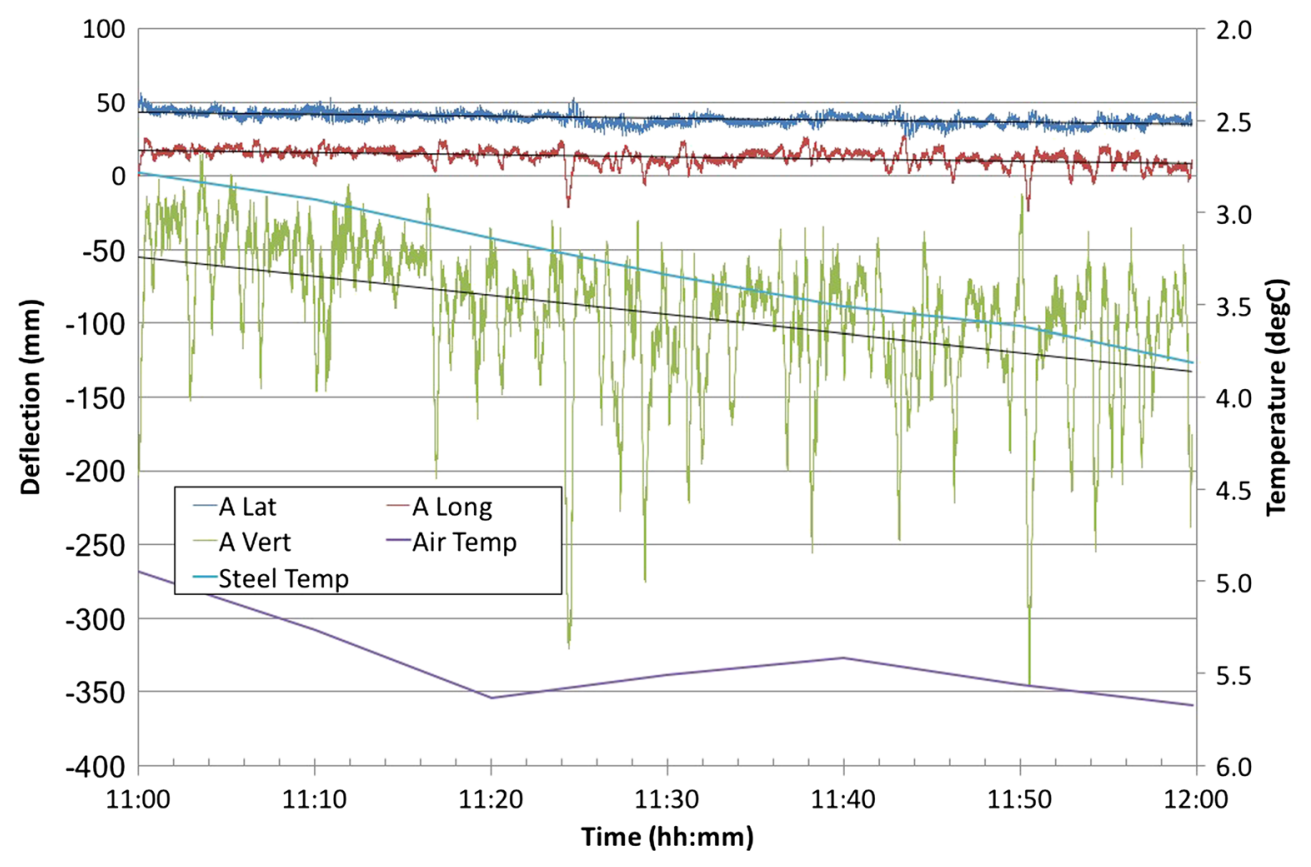


Fig. 5 Vertical movements at locations A, B, C and D over a 4-h period on the 10th March 2010

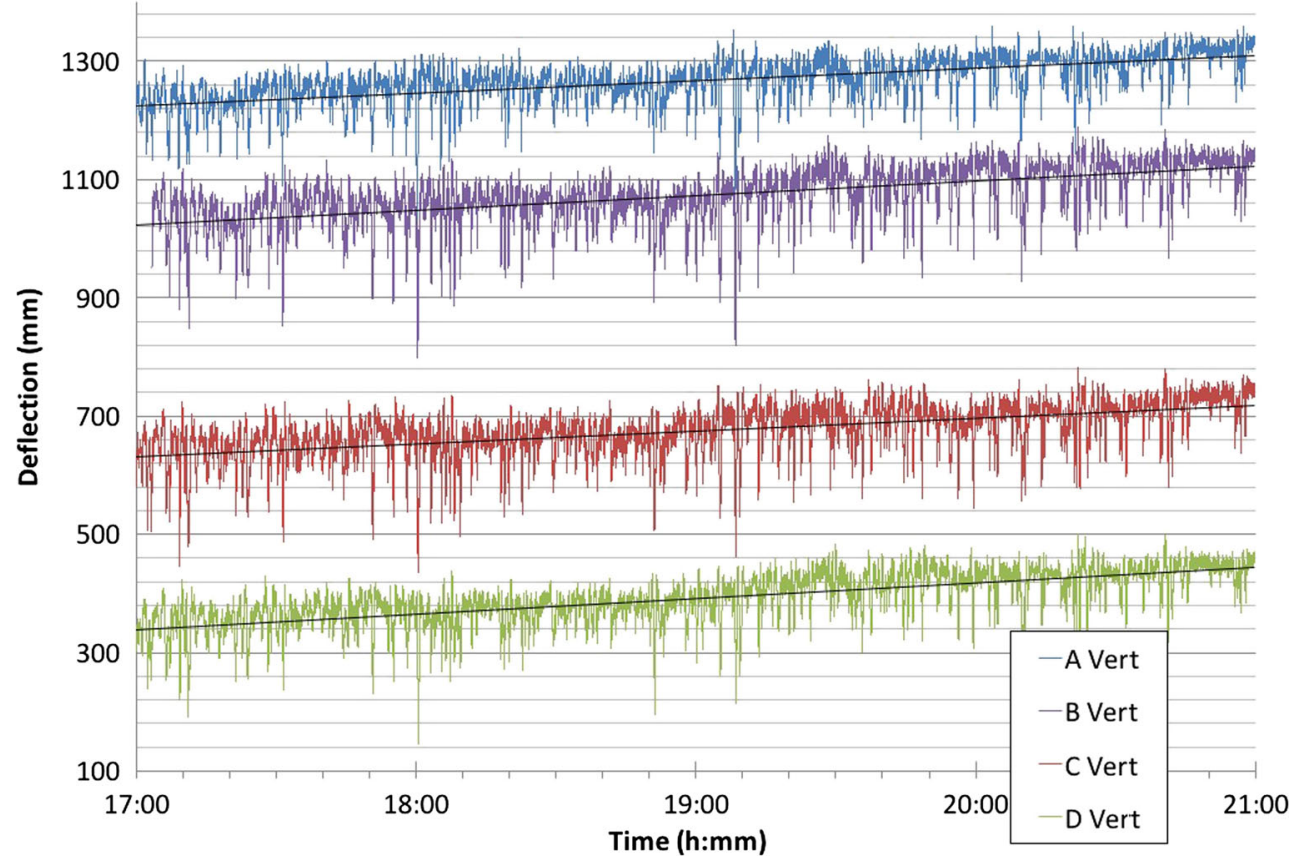

the movements in the longitudinal and lateral components of the bridge structure.

Long $=E \cos a+N \sin a$

Lat $=N \cos a-E \sin a$

Figure 4 illustrates typical movements of the Bridge at location A over a 1-h period on the 11th March, between 11:00 and 12:00, with corresponding air and steel temperature data. The temperature data have been inverted so as to help illustrate the trends in the movement and temperature data.
Here, it can be seen that there are short-term movements due to traffic loading in particular, resulting in movements of the order of up to $250 \mathrm{~mm}$ in the vertical direction, as well as smaller movements of the order of up to $30 \mathrm{~mm}$ in the longitudinal direction, and $10 \mathrm{~mm}$ in the lateral direction. The small lateral movements also imply that the wind velocity during this time was very small. This was the case when looking at the wind data available.

There are also short-term $0.146 \mathrm{~Hz}$ natural frequency movement data within these data (Roberts et al. 2014). The movement that is focussed on in this paper are the longer-term movement due to the change in temperature. During the 1-h
Fig. 6 Lateral, longitudinal and vertical movements at location $\mathrm{A}$, as well as the air and steel temperatures over the 3-day period 10th to 12th March 2010

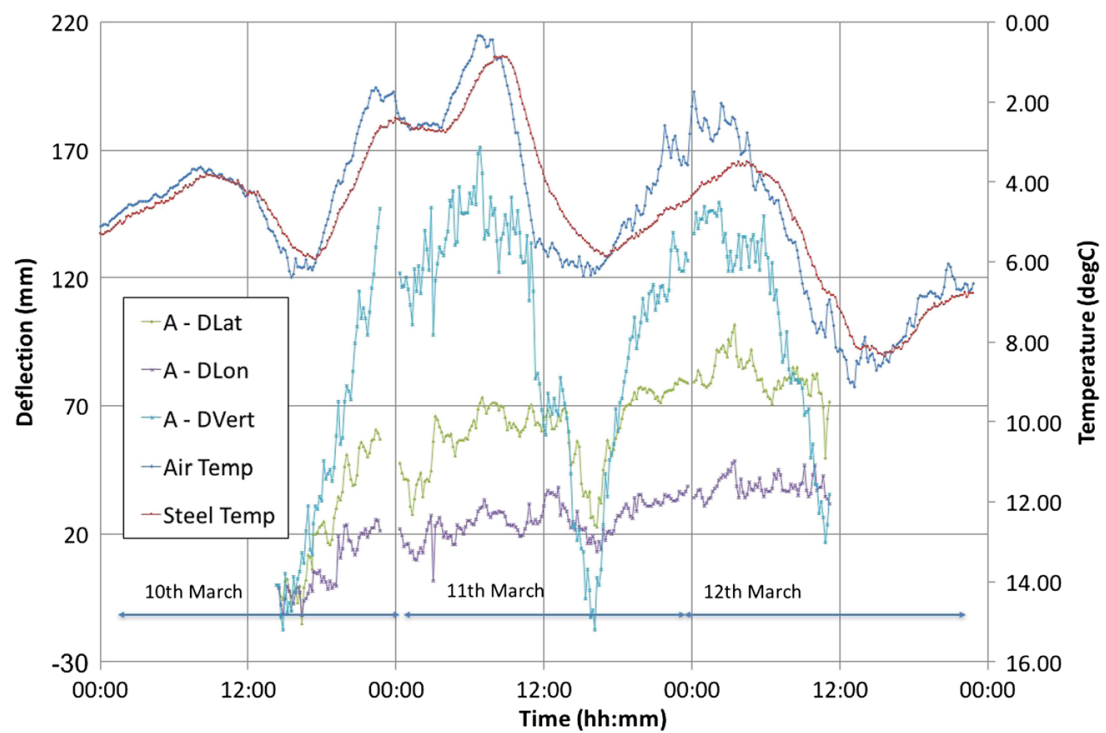




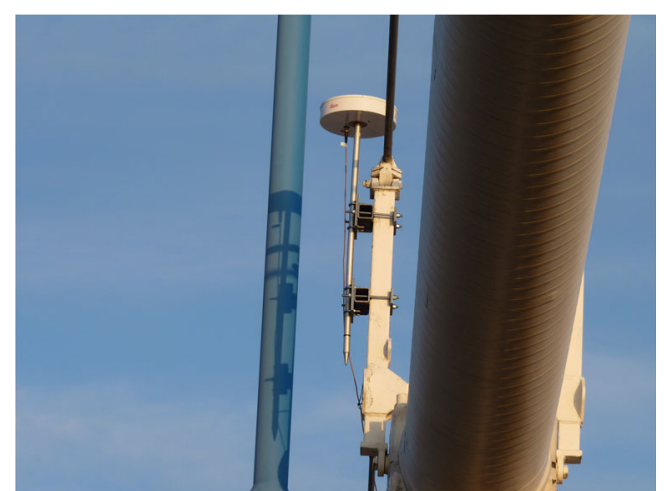

Fig. 7 Antenna located on the suspension cable

test period, Fig. 4, the air temperature changes from 4.9 to $5.7^{\circ} \mathrm{C}\left(0.7^{\circ} \mathrm{C} / \mathrm{h}\right)$, and the steel temperature changes from 2.8 to $3.8^{\circ} \mathrm{C}\left(1.0^{\circ} \mathrm{C} / \mathrm{h}\right)$. The corresponding change in the average vertical value for location A, Fig. 4 , is $78 \mathrm{~mm} / \mathrm{h}$, or $107.6 \mathrm{~mm} /{ }^{\circ} \mathrm{C}$ (air) and $75.5 \mathrm{~mm} /{ }^{\circ} \mathrm{C}$ (steel). Further to this, the corresponding change in the lateral direction for A is $8.3 \mathrm{~mm} /$ $\mathrm{h}$, and the corresponding change in the longitudinal direction is $8.7 \mathrm{~mm} / \mathrm{h}$.

Figure 5 illustrates the vertical component of the antennas at locations A, B, C and D over a 4-h period on the 10th March. This time, the data was gathered in the evening, when the air and consequently steel temperatures were dropping.

The average vertical cable locations during a period of air cooling in the evening (Fig. 5) become more positive in value - that is, move upwards. The air temperature changes from 6.1 to $2.6^{\circ} \mathrm{C}\left(-3.5^{\circ} \mathrm{C}\right.$ or $\left.-0.9^{\circ} \mathrm{C} / \mathrm{h}\right)$, and the steel temperature changes from 5.9 to $3.8^{\circ} \mathrm{C}\left(-2.1{ }^{\circ} \mathrm{C}\right.$ or $\left.-0.5{ }^{\circ} \mathrm{C} / \mathrm{h}\right)$ between
17:00 and 21:00. The corresponding change in the average vertical value for location $\mathrm{A}$ is $21 \mathrm{~mm} / \mathrm{h}$ or $23.9 \mathrm{~mm} /{ }^{\circ} \mathrm{C}$ (air) and $39.8 \mathrm{~mm} /{ }^{\circ} \mathrm{C}$ (steel). Further to this, the corresponding change in the lateral direction for $A$ is $10.5 \mathrm{~mm} / \mathrm{h}$, and the corresponding change in the longitudinal direction is $0.1 \mathrm{~mm} / \mathrm{h}$.

The temperature values for both the air and the steel at the Aust abutment of the Bridge are recorded at a 10-min interval. The data for location A was filtered with a moving average to correspond to the same 10-min interval. Figure 6 illustrates the relationship between the lateral, longitudinal and vertical movements of location A using the moving average filter, Eq. 3, as well as the air and steel temperatures over the 72-h period of the 10th to 12th March. The data for location A used in Figs. 4 and 5 are a subset of the data in Fig. 6. In Eq. 3, MA represents the moving average value of the 10 -min period $i, N$ represents the number of epochs within the 10 -min period, and $x_{j}$ represents the coordinate value at epoch $j$. The GPS results begin at 14:20 on the 10th and end at 11:10 on the 12th.

$\mathrm{MA}_{i}=\frac{1}{N} \sum_{j=1}^{N} x_{j}$

Figure 6 illustrates that there is correlation between the changes in temperature and the deflections measured using GPS. The temperature data have been inverted as previously mentioned. It can also be seen that the vertical component experiences the most movement, with peak movements of up to $188.5 \mathrm{~mm}$ being measured. However, the lateral component of the movements also experiences significant
Fig. 8 Lateral, longitudinal and vertical movements at location $\mathrm{A}$, as well as the air and steel temperatures over the 3-day period 10th to 12th March 2010

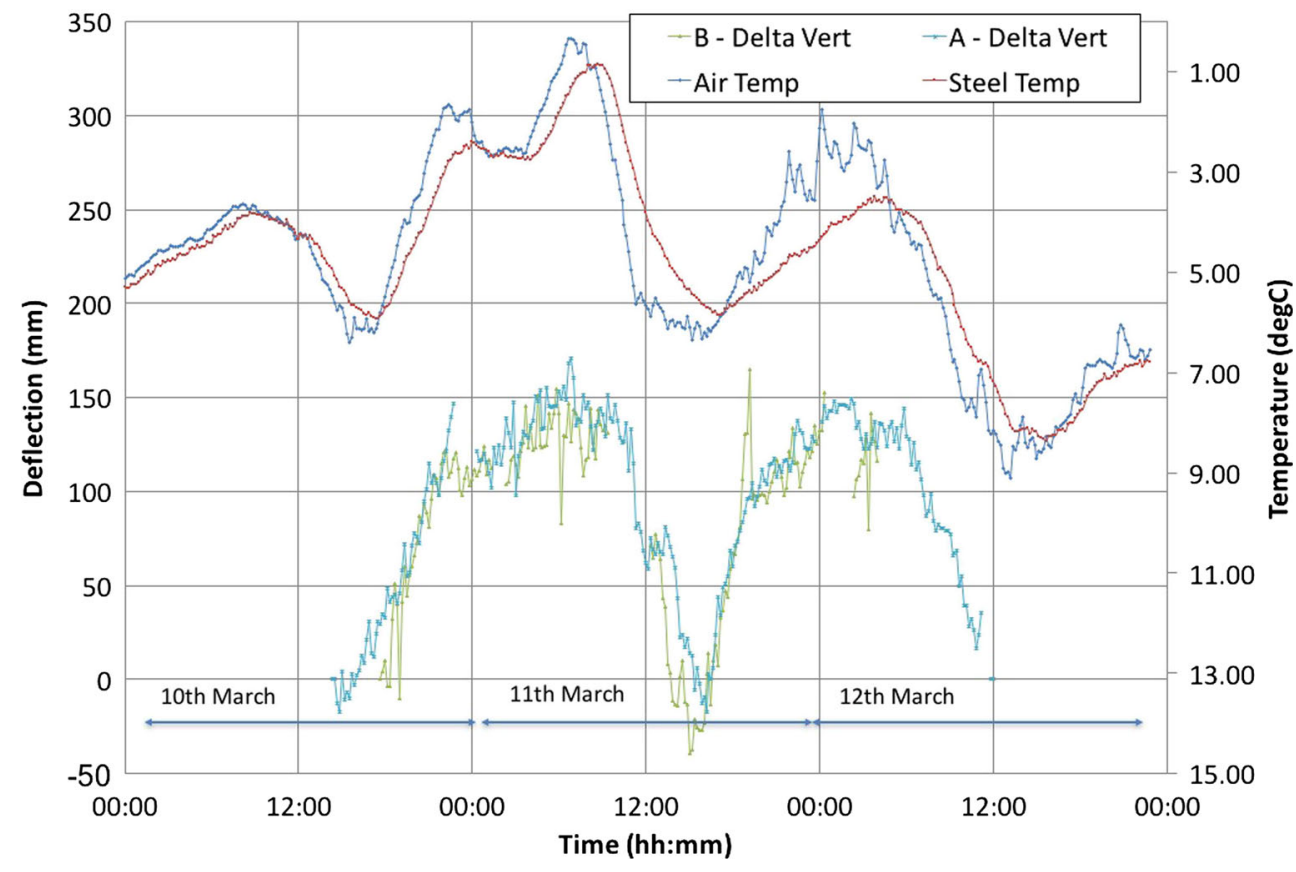


Table 1 The normalised cross-correlation coefficients for the air and steel temperatures with the vertical movements at locations A and B

\begin{tabular}{llllr}
\hline & Air Temp & Steel Temp & Avert & \multicolumn{1}{c}{ Bvert } \\
\hline Air Temp & 1.0000 & & & \\
Steel Temp & 0.8911 & 1.0000 & & \\
Avert & 0.8747 & 0.7537 & 1.0000 & \\
Bvert & 0.8061 & 0.6641 & 0.9116 & 1.0000 \\
Random & 0.0223 & 0.0026 & -0.0098 & -0.0363 \\
\hline
\end{tabular}

movements; peak movements of up to $78.2 \mathrm{~mm}$ are measured. The vertical component movements in Fig. 6 are due to the expansion of the cable, resulting in the cable drooping. There is also some evidence of movements in the longitudinal direction, as the cable expands, and location A is $164 \mathrm{~m}$ from the centre. Any expansion of the cable will result in movements in the longitudinal component for any location not located at the middle of the cable. The lateral component's movement is thought to be due to the direct heating effect on the cable through insolation. The bridge is orientated from Beachley to Aust at a bearing of $120^{\circ}$. This means that when the sun shines directly onto one side of the cable, this side expands more than the other side. The antenna, Fig. 7, is located on top of a mast. The conclusion is that as one side of the suspension cable expands quicker than the other, the mast will rotate about the longitudinal axis of the suspension cable and hence the small lateral movement is amplified.

Figure 8 illustrates the relationship between the air and steel temperatures with the vertical movements at locations $\mathrm{A}$ and $\mathrm{B}$ over the whole survey period. Again, the temperature data in this figure have been inverted so as to help illustrate the trends in the datasets. The data used in Figs. 4 and 5 are again subsets of the data used in Fig. 8. Location B is at the middle of the cable and location A is $164 \mathrm{~m}$ from the centre, on the cable. It can be seen that there are similarities in the trends of the vertical movement data at locations A and B. At 16:10 on the 11th March, it can be seen that location B dips lower than location A. This is as expected, due to location $\mathrm{B}$ being in the centre of the cable, and location A $164 \mathrm{~m}$ offset.

Correlation analysis was conducted on the resulting data for the 10-min epoch intervals for the air temperature, steel temperature and vertical deflections at locations A and B. In addition, random values were generated, within the same range as the true values of vertical deflections. Crosscorrelation analysis was conducted between the temperatures and themselves, the various datasets and the random values, as well as the air and steel temperatures with the vertical movements at locations A and B. One hundred sixty-two common 10-min epochs exist for all the data i.e. steel and air temperature as well as the deflections for locations A and B. The cross-correlation analysis for the various parameters is illustrated in Table 1. Here, it can be seen that when the values are correlated against themselves, the normalised crosscorrelation coefficients are all equal to 1.0000 , as expected. Table 1 also illustrates the low correlation coefficient values when the values are correlated against the random values, again as expected. Both these sets of results illustrate the expected range from a perfectly correlated pair of values, to a poorly correlated pair of values. The steel temperature and air temperature ranges correlate with a value of 0.8911 against each other. The remaining values in Table 1 illustrate that the vertical movements at locations A and B correlate with values of 0.8747 and 0.8061 against the air temperature, and 0.7537 and 0.6641 against the steel temperature ranges. The results show that there is a reasonably high level of correlation between the temperature results and the vertical movements. The
Fig. 9 Relationship between the change in temperature and change in height at location A on the 11th March

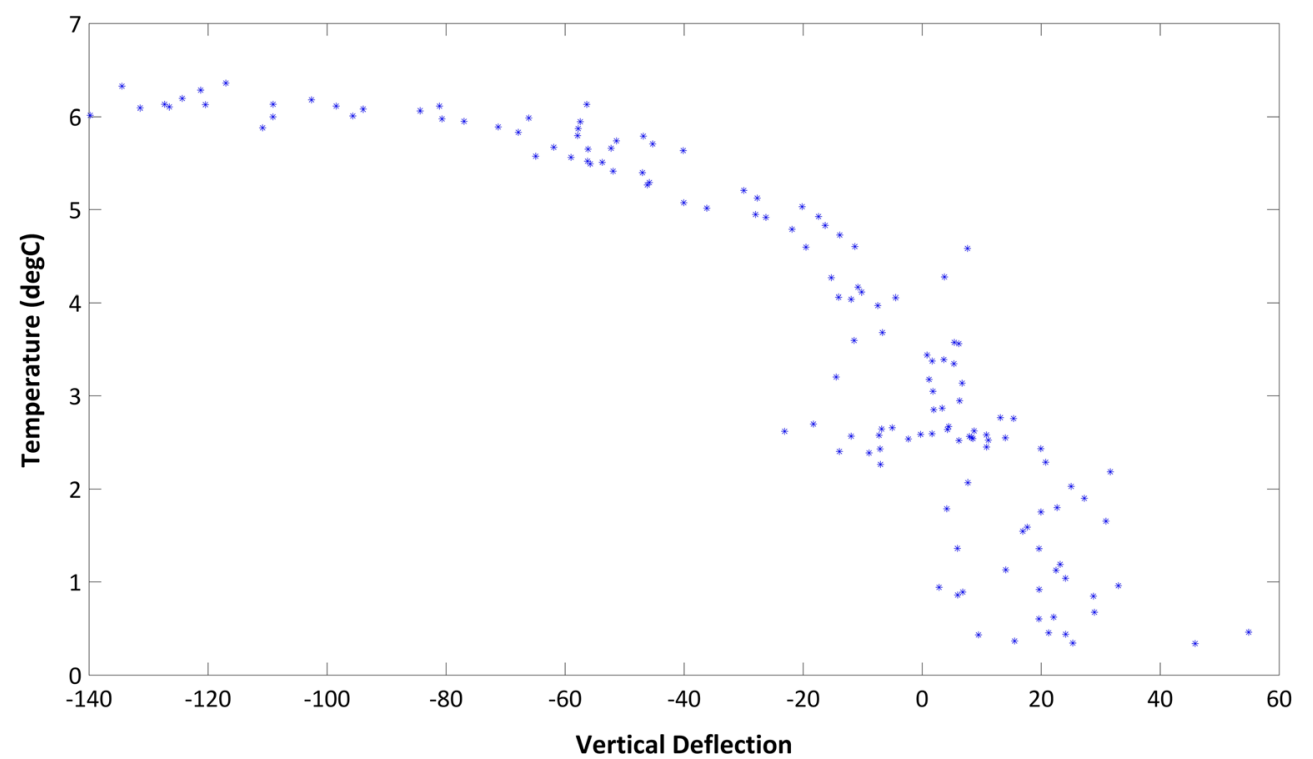


air temperature is better correlated than the steel temperature. The steel temperature is taken at the Aust abutment, and not at the suspension cable. Previous research has shown that the temperatures at two such locations can vary (Westgate et al. 2014). Location A has a higher correlation than location B with the temperature values, and is seen to correlate at a value of 0.8747 with the air temperature. The highest correlation value in Table 1 is seen to be the correlation between the vertical movements at locations $\mathrm{A}$ and $\mathrm{B}$ with each other, at a value of 0.9116 .

Figure 9 illustrates the relationship between the change in height at location $\mathrm{A}$ and temperature during the 10-min epochs, over the $24-\mathrm{h}$ period. This again shows that there is a good relationship between these data. Such results could be used to help model how the bridge behaves, and used in a structural monitoring scheme. Any deviations from such trends could be further investigated as this could indicate damage caused to the bridge.

\section{Conclusions}

The results show a clear relationship between the movements at the GNSS receivers on the Severn Bridge and the temperature of the steel and air. Previous work has focussed on longterm and daily results, whereas this work looks at more frequent data. The results illustrate a correlation of up to $87.47 \%$ between the air temperature and the vertical movements at location A. Further work is being carried out to investigate this relationship further for the whole of the survey in 2010 . In addition to this, work is underway to look at the relationship between these data as well as data gathered in July 2015, in order to investigate the repetition of such an approach. The temperature variation will then go up to $24{ }^{\circ} \mathrm{C}$, rather than only the $6{ }^{\circ} \mathrm{C}$ illustrated in this paper. Such understanding of the movements of a structure due to changes in temperature is an important factor when designing and also when monitoring the movements over a period of time. Through using simple filters, it is possible to extract various types of movements from the high-rate GNSS data, including the temperaturerelated movements focussed on in this paper. This could be carried out in an automated manner. Such an approach and knowledge can be used as part of a dynamic structural health monitoring system, resulting in sustainable and smart structures.

\footnotetext{
Acknowledgements This work was supported by Ningbo Science and Technology Bureau's International Academy for the Marine Economy and Technology 'Structural Health Monitoring of Infrastructure in Logistics Cycle' (2014A35008). The authors are also very grateful to the staff at the Severn Bridge Crossing plc and Skanska, in particular Adrian Burt and Jon Phillips, for their help and assistance in arranging and carrying out the field tests.
}

Open Access This article is distributed under the terms of the Creative Commons Attribution 4.0 International License (http:// creativecommons.org/licenses/by/4.0/), which permits unrestricted use, distribution, and reproduction in any medium, provided you give appropriate credit to the original author(s) and the source, provide a link to the Creative Commons license, and indicate if changes were made.

\section{References}

Ashkenazi V, Dodson AH, Moore T, Roberts GW (1996) Real time OTF GPS monitoring of the Humber Bridge. Surveying World 4(1):2628 ISSN 0927-7900

Atzeni C, Bicci A, Dei D, Fratini M, Pieraccini M (2010) Remote survey of the leaning tower of Pisa by interferometric sensing. IEEE Geosci Remote Sens Lett 7(1):185-189. doi:10.1109/LGRS.2009.2030903

Cosser E (2005) Bridge deformation monitoring with single frequency GPS augmented by pseudolites. PhD Thesis, The University of Nottingham, UK

De Battista N, Brownjohn JMW, Tan HP, Koo KY (2015) Measuring and modelling the thermal performance of the Tamar Suspension Bridge using a wireless sensor network. Struct Infrastruct Eng 11(2):176193. doi: $10.1080 / 15732479.2013 .862727$

Ferrer B, Mas D, Garcia-Santos JI, Luzi J (2016) Parametric study of the errors obtained from the measurement of the oscillating movement of a bridge using image processing. J Nondestruct Eval 35(53):3553. doi:10.1007/s10921-016-0372-6

Fisher J, Lambert P (2013) Severn bridge cables - corrosion models, use of inhibitors and their impact on the cable assessment. In: Proc.: 8th International Cable Supported Bridge Operators Conference, Edinburgh

Gentile C, Cabboi A (2015) Vibration-based structural health monitoring of stay cables by microwave remote sensing. Smart Struct Syst 16(2):263-280. doi:10.12989/sss.2015.16.2.263

Kitagawa M (2004) Technology of the Akashi Kaikyo Bridge. Journal of Structural Control and Health Monitoring 11(2):75-90. doi:10. $1002 /$ stc. 31

Luzi G, Crosetto M, Cuevas-González M (2014) A radar-based monitoring of the Collserola Tower (Barcelona). Mech Syst Signal Process 49:234-248. doi:10.1016/j.ymssp.2014.04.019

Matsumoto M, Shirato H, Yagi T, Shijo R, Eguchi A, Tamaki H (2003) Effects of aerodynamic interferences between heaving and torsional vibration of bridge decks: the case of Tacoma Narrows Bridge. J Wind Eng Ind Aerodyn 91(12-15):1547-1557. doi:10.1016/j.jweia. 2003.09.010

Meo M, Zumpano G, Meng X, Roberts GW, Cosser E, Dodson AH (2004) Identification of Nottingham Wilford Bridge modal parameters using wavelet transforms. In: Smith Ralph C (ed) peer-refereed Proc of SPIE, Smart Structures and Materials 2004: Modeling, Signal Processing, and Control, July 2004, Vol. 5383: 561-570

Negulescu C, Luzi G, Crosetto M, Raucoules D, Roullé A, Monfort D, Pujades L, Colas B, Dewez T (2013) Comparison of seismometer and radar measurements for the modal identification of civil engineering structures. Eng Struct 51:10-22. doi:10.1016/j.engstruct. 2013.01.005

Ogundipe O, Roberts GW, Brown CJ (2014) GPS monitoring of a steel box girder viaduct. Structure and infrastructure engineering: maintenance, management, life-cycle design and performance. 10(1): 25-40. doi:10.1080/15732479.2012.692387

Roberts GW, Brown CJ, Meng X (2005) The use of GPS for disaster monitoring of suspension bridges. Proceedings of the IAG Congress, 21-25 August 2005, Cairns, Australia

Roberts GW, Meng X, Brown CJ, Dallard P (2006) GPS measurements on the London Millennium Bridge. PROCEEDINGS- 
INSTITUTION OF CIVIL ENGINEERS BRIDGE ENGINEERING 159(4):153-162. doi:10.1680/bren.2006.159.4. 153 ISSN: 1478-4637. E-ISSN: 1751-7664

Roberts GW, Brown CJ, Meng X, Ogundipe O, Atkins C, Colford B (2012) Deflection and frequency monitoring of the Forth Road Bridge, Scotland, by GPS. Proceedings Institution of Civil Engineers - Bridge Engineering 165(BE2):105-123. doi:10.1680/ bren.9.00022

Roberts GW, Brown CJ, Tang X (2014) A tale of five bridges; the use of GNSS for monitoring the deflections of bridges. The Journal of Applied Geodesy 8(4):241-264. doi:10.1515/jag-2014-0013 ISSN 1862-9024

Shackman L, Climie D (2016) Planning and procurement of the Queensferry Crossing in Scotland. Proc Inst Civil Eng Civ Eng. Published online June 172016 ahead of print. doi:10.1680/jcien. 16.00006

Stephen GA, Brownjohn JMW, Taylor CA (1993) Measurements of static and dynamic displacement from visual monitoring of the Humber
Bridge. Eng Struct 15(3):197-208. doi:10.1016/0141-0296(93) 90054-8

Takasu T, Yasuda A (2009) Development of the low-cost RTK-GPS receiver with an open source program package RTKLIB. International Symposium on GPS/GNSS, International Convention Center Jeju, Korea, November 4-6, 2009

Westgate R, Koo KY, Brownjohn J (2014) Effect of solar radiation on suspension bridge performance. American Society of Civil Engineering; Journal of Bridge Engineering 20(5):04014077. doi: 10.1061/(ASCE)BE.1943-5592.0000668

Xia Y, Brownjohn JMW, Koo KY (2016) Temperature analysis of a longspan suspension bridge based on field monitoring and numerical simulation. American Society of Civil Engineering; Journal of Bridge Engineering 21(1). doi:10.1061/(ASCE)BE.1943-5592. 0000786

Xu YL, Chen B, Ng CL, Wong KY, Chan WY (2010) Monitoring temperature effect on a long suspension bridge. Struct Control Health Monit 17(6):632-653. doi:10.1002/stc.340 